\title{
Comment
}

Neuroepidemiology 2009;32:70-71

DOI: $10.1159 / 000170909$

\section{Vital Records and Dementia}

Lewis H. Kuller, Diane G. Ives

Department of Epidemiology, Graduate School of Public Health, University of Pittsburgh, Pittsburgh, Pa., USA

Zilkens et al. [1] have demonstrated the importance of understanding the magnitude and impact of misclassifying cause of death on mortality data and vital statistics. The authors reported death rates for people with a dementia diagnosis for underlying cause of death, contributory cause of death, and lifetime history were estimated at 10.6 (95\% CI: 16.9-22.3), 50.1 (45.7-54.4) and $79.4(74.0-84.8)$ per 100,000 person-years, respectively. This extremely wide range of rates would result in very different interpretation and potential action.

The recognition and diagnosis of dementia have undergone considerable changes, which may be reflected in the death certificate coding of dementia, rather than true trends in the incidence and prevalence of the disease. Previous studies suggest that death certificates, compared with other data sources, may misclassify the underlying cause of death, especially in older individuals with multiple comorbidities. This misclassification has been attributed, in part, to variations in coding, limitations of the death certificate format, and changing trends in the science of diagnosis [2, 3]. Immediate causes of death in demented subjects are frequently listed as the underlying cause of death such as pneumonia, sepsis, fatal fractures, and stroke while omitting the dementia entirely. Additionally, physicians tend to overstate cardiovascular causes of death compared with subsequent autopsy or review of hospital discharge data [4]. Physicians may hesitate to list dementia on the death certificate because of perceived social stigmata of the diagnosis or limitations of reimbursements for care prior to death.

Diseases such as Alzheimer's disease (AD) represent a leading cause of death in the elderly. Beginning with mortality data for 1994 , AD became common enough in the USA to become a major category of cause of death [5]. In some populations only a quarter of deaths in demented patients had this disease on the death certificate [6]. Similar underreporting of deaths related to vascular dementia takes place [7]. In some studies, less than half of vascular-dementia-related deaths were correctly classified [8]. Inaccuracies in coding practices of dementia have a direct impact on mortality data and vital statistics. This paper has shown how extremely different those statistics would be if they were based on the different coding strategies. These issues are reflected in misclassification and subsequently impact the vital statistics they represent [9].

The use of ICD codes and discharge diagnoses from face sheets of hospital records can also contribute to misclassification. Through our experience in the Cardiovascular Health Cognition Study [10], medical records were reviewed for evidence of dementia in subjects who were not evaluated in person. This was done so as not to miss dementia ascertainment in subjects unable to be assessed in person because their impairment prevented their participation in the research. Frequently, dementia is not listed as part of the hospitalization discharge codes because the admission may be due an unrelated or acute condition. Yet review of the actual hospital record revealed clear evidence of an underlying dementia including specific diagnostic evaluations, use of medications specific to dementia treatment, and clear evidence of criteria related to cognitive abilities and limitations. Without careful review of the actual hospital records for a dementia diagnosis, the condition would have been missed. The complex and often large number of comorbid conditions present in the elderly patients having the highest prevalence of dementia often compound the complexities of identifying cases.

One major limitation of using hospital or other administrative data bases is whether the diagnosis of dementia is accurate, especially among patients with diseases that may be associated with depression and delirium that may be confused with dementia. Second, we do not know the completeness of ascertainment of all of the cases of dementia in a defined population using hospital data and also whether the ascertainment is biased by social demographic variables, prevalence of other diseases and the frequency of hospitalization. Use of other health and social service records may improve ascertainment of dementia cases [11]. As the population at greatest risk for dementia continues to grow, more consistent and reliable methods of tracking morbidity and mortality from dementia must be developed. Hopefully, in the not too distant future, we may be able to study the epidemiology of dementia and specific types of dementia using vital records as a primary source of case ascertainment as we do now with studies of stroke, cardiovascular disease and cancer.

\section{References}

1 Zilkens RR, Spilsbury K, Bruce DG, Semmens JB: Linkage of hospital and death records increased identification of dementia cases and death rate estimates. Neuroepidemiology 2009;32:61-69.

2 Johansson LA, Westerling R: Comparing hospital discharge records with death certificates: can the differences be explained? J Epidemiol Community Health 2002;56:301-308.

-3 Shayoun NR, Lentzer H, Hoyert D, Robinson KN: Trends in causes of death among the elderly. Aging Trends 2001;1:1-10.

\section{KARGER}

Fax +41613061234 E-Mail karger@karger.ch www.karger.com
C 2008 S. Karger AG, Base

0251-5350/09/0321-0070\$26.00/0 
4 Lakkireddy DR, Gowda MS, Murray CW, Basarakodu KR, Vacek JL: Death certificate completion: how well are physicians trained and are cardiovascular causes overstated? Am J Med 2004;117:492-498.

5 Hoyert DL, Rosenberg HM: Alzheimer's disease as a cause of death in the United States. Public Health Rep 1997;112:497-505.

6 Ganguli M, Rodriguez EG: Reporting of dementia on death certificates: A community study. J Am Geriatr Soc 1999;47:842-849.

7 Dollear W, Gorelick PB, Miles T, Bozzola F: Vascular dementia: A clinical and death certificate study. Neuroepidemiology 1992;11:53-58.

8 Thomas BM, Starr JM, Whalley LJ: Death certification in treated cases of presenile Alzheimer's disease and vascular dementia in Scotland. Age Ageing 1997;26:401-406.

9 Ives DG, Samuel P, Psaty BM, Kuller LH: Agreement between nosologist and Cardiovascular Health Study review of deaths: Implications of coding differences. J Am Geriatr Soc, in press.
10 Lopez OL, Kuller LH, Becker JT, Dulberg C, Sweet RA, Gach HM, DeKosky ST: Incidence of dementia in mild cognitive impairment in the Cardiovascular Health Study Cognition Study. Arch Neurol 2007; 64:416-420.

11 Phung KTT, Waltoft BL, Kessin, Morensen PB, Waldemar G: Is dementia underdiagnosed? A nationwide population-based study using national registers. Alzheimers Dement 2008;4:T706.

Lewis H. Kuller, MD, DrPH

Department of Epidemiology, Bellefield Professional Building Room 550, 130 North Bellefield Avenue

Pittsburgh, PA 15213 (USA)

Tel. +1 412383 1895, Fax +1 4123831956

E-Mailkullerl@edc.pitt.edu 